\title{
Editorial
}

\section{The world, out there}

The Royal Society published in late June a report entitled «Science Communication. Survey of factors affecting science communication by scientists and engineers». ${ }^{1}$ It is an in-depth survey on the communication addressed to non-specialist audiences that was carried out interviewing a wide and representative sample of UK scientists and engineers.

Some of the results of this study are totally unexpected. Scientists in the UK are not engaged with the media and do not communicate science to the general public. In the past 12 months, $75 \%$ of scientists surveyed said that they had written neither articles nor books; $77 \%$ had not been interviewed by newspaper journalists; $80 \%$ had not taken part in a public event about science (debates); $88 \%$ had not been interviewed on the radio; $89 \%$ had not worked with science centres or museums; $70 \%$ had not worked with teachers nor students.

The most frequent activity $(56 \%)$ is probably a compulsory one: the participation in an institutional open day events, when the doors are opened and crowds of non-specialist visitors enter the laboratories.

To us, these are particularly significant figures. The United Kingdom is at the forefront in the promotion of the relations between «science and society» and in public scientific communication. Nevertheless, only a limited minority of its science and technology experts are engaged with public opinion in a systematic way. Only a scarce $2 \%$ of the interviewees published at least four articles in newspapers over a year, only $2 \%$ were interviewed more than four times on the radio; only $5 \%$ visited a school more than four times; only $2 \%$ were involved in the activities of a museum or science centre; only $1 \%$ took part in at least four public debates.

If these are the figures reported in the United Kingdom, a country believed to be among the most developed in the relation between "science and society", then much remains to be done in the relations between scientists and public opinion. Or perhaps much remains to be understood about the actual prospects for direct and systematic communication between scientists and public opinion.

The survey by the Royal Society, however, does not merely illustrate this negative state of affairs. It also presents a significant cross-section of the way communication with non-specialist audiences is perceived by science and technology experts.

Of those surveyed, only $12 \%$ said that communication with the general public is truly relevant, whereas a limited $10 \%$ said that the relation with general journalists is really important. Communication with policy-makers is the one perceived to be the most important: 60\% said it is important and $35 \%$ very important. Communication with industry and the productive system ranks second: it is thought to be important by $47 \%$ of the interviewees and very important by $22 \%$. Teachers and students come third: $50 \%$ of the interviewees said that being engaged with them is important, whereas $20 \%$ said it is very important. Communication with popular science journalists is not deemed decisive: $45 \%$ of the interviewees stated it is important and only $18 \%$ viewed it as very important.

The satisfaction level related to this inadequate and quite opportunistic communication activity is more predictable.

The groups that UK science and technology experts find it easiest to communicate with are science journalists and industrialists (both selected by $29 \%$ ), followed by teachers and students (23\%).

The groups the UK scientists and technicians find it hardest to communicate with are general journalists (selected by $21 \%$ ) and policy-makers (19\%), followed by the general public (15\%).

The most critical relation appears to be precisely the one with policy-makers: it is, at the same time, the most relevant and the most frustrating one. On the other hand, relations with mass media appear to be put into perspective as scant, very frustrating and rather irrelevant.

A closer look thus reveals that what emerges from the Royal Society survey is a scientific community that is still trapped in its splendid isolation and is rather uncomfortable in its timid relations with society. It does not like the world out there and does not understand it. It does establish some communication channels, but only if and when they are deemed to be truly necessary.

Given this the high frustration level is hardly surprising. 
We have the impression that it will take very long before scientists and technicians can relax and be less suspicious and possibly start appreciating some features of the chaotic world beyond the high walls of their isolation.

Whatever the case may be, the sooner the better for everyone.

The world is not easy, out there. But it is a living world. It changes and can be improved. In any case, this is the world we have to live in.

Pietro Greco

Translated by Massimo Caregnato

\section{Notes and references}

${ }^{1}<\underline{\text { http://www.royalsoc.ac.uk/downloaddoc.asp?id=3074> }}$ 